\title{
Las Especies son Linajes de Poblaciones Microevolutivamente INTERCONECTADAS: Una Mejor Delimitación del Concepto Evolucionario de Especie
}

\author{
Gustavo Caponi
}

\begin{abstract}
Species can be defined as a lineage of populations among which was never set up an micro-evolutionary isolation, and what is meant by 'micro-evolutionary isolation' is this: two populations are micro-evolutionarily isolated, if and only if, the micro-evolutionary processes affecting one of them (namely: natural selection, genetic drift, sexual selection, mutation and/or migration) cannot reach the other. This is a delimitation of the evolutionary species concept that is compatible and solidary with the conceptual division of labor that some authors have proposed to solve the problem raised by the definition of species.
\end{abstract}

Keywords: Definition of species; evolutionary species concept; micro-evolutionary isolation.

De un concepto único de especie, que contemple todos los usos legítimos y reconocidos que los biólogos hacen del término, parece esperarse mucho. Algunos dirían que demasiado. Ese concepto debería aplicarse tanto a especies sexuadas como asexuadas. Lo que puede terminar abarcando a las siempre desconcertantes bacterias. También debe esperarse, por otro lado, que la intensión ${ }^{1}$ de ese concepto reconozca el carácter temporal de las especies (cf. Wiley 1992[1978], p.79). El concepto de especie que permite decir que Canis lupus dingo, el dingo australiano, y Canis lupus baileyi, el lobo mexicano, son dos subespecies de Canis lupus, debe también permitir atribuirle ese estatuto al lobo negro de Florida, extinguido en 1908. Debe permitirnos decir que Canis lupus floridanus fue una subespecie de esa misma especie que aún perdura y que denominamos Canis lupus. Un concepto de especie, además, debe también permitirnos darle alguna justificación al hecho de que los lobos de Ontario, que integran la subespecie Canis lupus lycaon, sean considerados como parte de la misma especie de los dingos, con los cuales nunca se saludan, pero no sean considerados de la misma especie que los coyotes que componen Canis latrans, con los cuales suelen aparearse generando híbridos fértiles.

Un concepto único de especie debe ser compatible, por otra parte, con las reglas que rigen el funcionamiento de esa noción en los más diversos campos de la Biología: la Paleontología, la Ecología, la Genética de Poblaciones, la Biogeografía, la Sistemática, etc. Y eso, conforme ya dije, parece ser demasiado. Sobre todo cuando a la consideración de ese eje disciplinar se le superpone aquél otro que tiene que ver con la separación entre los dominios de la Botánica, de la Zoología, o la Micología. En

Principia 17(3): 395-418 (2013).

Published by NEL — Epistemology and Logic Research Group, Federal University of Santa Catarina (UFSC), Brazil. 
Ecología, cabría pensar, el concepto de especie funciona según reglas que no son las que rigen su aplicación en Sistemática; y una cosa es lo que ocurre con ese concepto en Fitogeografía y otra cosa totalmente diferente es lo que puede ocurrir con él en Bacteriología. Todo parece hacer recomendable un pragmático y prudente pluralismo que sepa reconocer una red de diferentes conceptos de especies, siempre unidos por un elusivo aire de familia (cf. Williams 1992; Ereshefsky 1992). ${ }^{2}$ Pero, pese a que esa resignación wittgensteiniana parezca lo más conveniente (Mishler 2010), los esfuerzos por delimitar y precisar un concepto único y unificador de especie, no han dejado de sucederse; ${ }^{3}$ y a ellos quiero sumarme. ${ }^{4}$

No con una propuesta que pueda considerarse demasiado original; sino con una propuesta que sólo pretende afinar el concepto evolutivo de especie, sin desconocer lo que otros conceptos de especie, como el biológico y el ecológico, ya han contribuido para la de limitación de dicha noción. Una especie, diré, puede ser definida como un linaje de poblaciones entre las que nunca se llegó a establecer un aislamiento microevolutivo. Esa definición, que desarrollaré más adelante, es una delimitación del concepto evolucionario de especie que resulta compatible y solidaria con la idea de división conceptual del trabajo que algunos defensores del concepto evolucionario como Richard Mayden (1999, p.100), Kevin De Queiroz (2007, p.882), y Richard Richards (2007, p.220) han propuesto para resolver el problema suscitado por la pluralidad de definiciones de especie que, con distintos fines, han sido enunciadas. ${ }^{5}$

Explicaré más adelante en qué consiste esa división conceptual del trabajo. Entenderla supone saber algo sobre las diferentes tentativas de elucidar el concepto de especie que se han ensayado desde que Dobzhansky (1935, p.353) y Mayr (1942, p.120) propusieron el llamado concepto biológico de especie (cf. Génermont 1998, p.37; Richards 2010, p.99). ${ }^{6}$ Sin conocer por lo menos las más influyentes y reconocidas de esas tentativas, y sin tener presentes las definiciones de especie a la que las mismas dieron lugar, esa división conceptual del trabajo resultaría incomprensible; como tampoco sería comprensible la versión del concepto evolucionario de especie que aquí pretendo esbozar. El concepto biológico de especie, el propio concepto evolucionario, así como el ecológico, el filogenético, y hasta el morfológico, nos permiten ver partes o aspectos de la propuesta que aquí he de presentar. Por eso, en las páginas que siguen analizaré algunos esos otros conceptos, no en todos los casos con el mismo detalle, para después delinear mi alternativa, mostrando cómo es que ella también apunta en la dirección de Mayden (2002, p.184), de Richards (2010, p.113), y de De Queiroz (2011, p.28).

\section{El concepto biológico de especie y sus problemas}

Según la enunciación del concepto biológico de especie consagrada por Mayr (2007 [1963] p.205; 2000, p.17), "las especies son grupos de poblaciones naturales en- 
trecruzables que están reproductivamente aisladas de otros grupos semejantes"; ${ }^{7}$ y no son pocos los biólogos actuales que la subscribirían. Esa definición de especie ha tenido una importancia crucial en el desarrollo de la Biología contemporánea ${ }^{8}$ y anunciar su eclipse sería un apresuramiento. En general, ella sigue siendo la primera a ser considerada cuando se quiere presentar el concepto de "especie"; y eso es algo muy significativo. En Evolution, por ejemplo, Douglas Futuyma (2005, p.354) presenta casi todas las definiciones más reconocidas de especie, sin impugnar ninguna. Pero a la hora de valerse de una de ellas para referirse a la temática de la especiación, que es sobre lo que quiere hablar, no duda en escoger a la definición biológica, olvidándose sumariamente de las otras. "Las especies biológicas", nos dice Futuyma (2005, p.363), "son definidas como poblaciones reproductivamente aisladas"; 9 y todo lo demás, diría uno, es literatura. ${ }^{10}$

Es obvio, sin embargo, que este concepto no puede aplicarse a seres vivos con reproducción exclusivamente uniparental, o asexuada; ${ }^{11}$ ahí la idea de cruzamiento no parece tener sentido. Esa es una dificultad que Mayr (2007[1963] p.211) y los demás defensores del concepto biológico de especie siempre reconocieron. ${ }^{12}$ Dobzhansky (1951, p.274), incluso, llega a afirmar que los organismos de reproducción asexuada no formaban verdaderas especies; ${ }^{13}$ y su actitud radical (Dobzhansky 1966[1962], p.67) parece corroborar la presunción que todo pretendido concepto único de especie sólo puede resultar en un inservible lecho de Procusto sobre el que la Biología, plural e insujetable, jamás podría reposar. ${ }^{14}$ Como sea, creo que esa dificultad también aqueja a la idea de especie como grupo de poblaciones de organismos con un sistema de fertilización común, que fue propuesta por Hugh Paterson (1985, p.25). La misma es una variante, o una generalización, del concepto biológico (Sterelny \& Griffiths 1999, p.193), y aunque en sus aplicaciones concretas ambos conceptos no sean equivalentes (Paterson, 1992, p.151-2), en lo que atañe al punto ahora discutido, no hay mucha diferencia entre ellos. ${ }^{15}$

Otra objeción, no menos seria, para el concepto biológico de especie, tiene que ver con la propia hibridación interespecífica (cf. Diégues 2012, p.222). Esa cuestión ya la había planteado Julian Huxley (1940, p.17; 1963[1943], p.157) cuando Dobzhansky presentó su propia formulación del concepto en cuestión; y George Gaylord Simpson (1951, p.289; 1961, p.152) hizo lo mismo, pero refiriéndose ya al propio Mayr, ${ }^{16}$ que más tarde también terminó admitiendo esa dificultad (Mayr 1988, p.331). Pero en aquellos primeros años, cuando la Nueva Síntesis todavía era nueva, no se pensaba que el fenómeno fuese tan común (cf. Mayr 1942, p.260; Lack 1947, p.95); y eso le quitaba peso a la objeción. La hibridación era una parte más de ese séquito murmurante de anomalías que siempre acompaña a las grandes ideas científicas.

Hoy, en cambio, es sabido que se trata de un fenómeno frecuente; ${ }^{17}$ no sólo entre plantas (Dobzhansky et al, 1980, p.192), sino también entre animales: tal como 
ocurre con el lobo y el coyote (Templeton 1992, p.166), y con varias especies de pinzones de Galápagos (Grant \& Grant, 2008, p.92). Las barreras reproductivas, puede entonces pensarse, no parecen tan relevantes a la hora de delimitar especies. ${ }^{18} \mathrm{Re}$ conocemos como constituyendo especies diferentes a conjunto de poblaciones cuyo aislamiento reproductivo dista de ser perfecto; y un concepto de especie que contemple ese hecho, debe poder darnos una razón para que, no obstante su persistente capacidad de cruzarse dando hibrido fértil, sigamos considerando que el coyote y el lobo son especies diferentes.

La dificultad, entiéndaselo, no está en la propia imperfección del aislamiento reproductivo. Al final de cuentas, se trata de un fenómeno natural que resulta de la propia evolución; y eso ya nos induce a pensar a ese aislamiento como siendo un proceso progresivo, gradual, y que puede llegar más o menos lejos. ${ }^{19}$ La propia especiación, podemos incluso decir, es un proceso gradual (Chambers 2012, p.760); y la propia idea de especie incipiente (Mayr 1942, p.155), que suele usarse como equivalente de subespecie (Dobzhansky et al. 1980, p.168), ya nos habla de procesos de especiación avanzados pero aun no plenamente consumados (Chambers 2012, p.762) ${ }^{20}$ En ese sentido, la respuesta que Mayr (2007[1963] p.210) da para esa dificultad parece correcta:

\begin{abstract}
Muy pocos mecanismos de aislamiento son dispositivos de todo o nada. Ellos se construyen paso a paso, y la mayoría de los mecanismos de aislamiento de una especie incipiente son imperfectos e incompletos. El grado de especie es alcanzado cuando el proceso de especiación llega a ser irreversible, aunque algunos de los mecanismos secundarios de aislamiento no hayan alcanzado la perfección.
\end{abstract}

La cuestión, sin embargo, está en encontrar la razón, si es que existe y no se trata de una cuestión de simple convención, para que consideremos, como la nomenclatura nos invita a hacerlo, que Canis lupus y Canis latrans, así como otras 'especies entrecruzables', constituyen realmente especies diferentes y no meras subespecies o especies incipientes. Y lo cierto es que, aparentemente, esa razón existe: pese a sus eventuales saltos de la cerca, lobo y coyote se mantienen como unidades biológicas independientes (Templeton, 1992, p.166). Los taxones Canis lupus y Canis latrans, según nos dice Alan Templeton (1992, p.168), "a menudo han sido reconocidos como especies en virtud de sus morfologías y ecologías distintivas y porque estudios moleculares modernos revelaron que ellos se comportan como linajes evolutivamente independientes". El problema es que esa idea de unidad biológica independiente, además de ya estar afuera de la intensión originaria del concepto biológico de especie, tampoco es muy fácil de definir: ¿ qué significa, sobre todo, que el coyote y el lobo se comporten como linajes evolutivamente independientes? Y por otra parte: ¿̇en qué sentido el coyote y el lobo son más independientes entre sí que el dingo y el lobo mexicano?

Principia 17(3): 395-418 (2013). 
Pero ya veremos eso a la hora de presentar los conceptos evolutivo y ecológico de especie, por ahora déjeseme aludir a otras dos dificultades que también parecen restarle crédito al concepto biológico de especie. Me refiero a la dificultad, ya reconocida por Mayr (2007[1963] p.206), de aplicarlo a especies muy separadas temporal y espacialmente. En perfecta alopatría, se podría decir, el aislamiento reproductivo de las poblaciones es muy difícil de confirmar; y así siempre nos faltarían elementos de juicio para decidir si dos supuestas subespecies de una misma especie efectivamente lo son, o si ellas ya son especies separadas. ${ }^{21} \mathrm{Y}$ lo que ocurre con la alopatría es semejante a lo que ocurre cuando nos preguntamos por poblaciones temporalmente muy distantes (Ayala, 2005, p.19): ¿ las poblaciones de Homo erectus era parte (formaban una subespecie) de la misma especie que hoy integran las poblaciones de Homo sapiens? ¿ O eran una especie distinta? ¿ Y qué decir de Homo sapiens y Homo neanderthalensis?

Creo, sin embargo, que no es correcto derivar de ahí una objeción o una impugnación al concepto biológico de especie. Del mismo modo en que una definición de verdad no debe confundirse con un criterio de verdad - es decir: del mismo modo en que definir qué es la verdad no implica ni exige suministrar un procedimiento para reconocerla - , definir qué es una especie, no implica, ni exige, dar [ipso facto] un criterio o procedimiento para identificar y diferenciar especies. Reconocer eso ya es aproximarse a la idea de división del trabajo conceptual que ahora se propone como marco para la resolución del problema suscitado por la definición de especie.

La definición biológica de especie, como cualquier otra definición posible de especie, deberá ser aplicada recurriendo a diversos criterios operacionales, que sean compatibles con ella y a los que ella les dé sentido. ${ }^{22} \mathrm{Si}$ la perfecta alopatría de dos poblaciones, o la extinción de una de ellas, no nos permite saber si ellas son, o fueron, capaces de cruzarse, otros criterios, otros datos, podrán ser usados para determinar si ellas son, o fueron, parte de la misma especie. Aunque es posible que, en muchos caso, nunca podamos saberlo a ciencia cierta. Con la verdad, otra vez, ocurre algo semejante: que sepamos qué es la verdad, no significa que tengamos recursos para develarla.

\section{La insuficiencia de los conceptos evolutivo y ecológico de especie}

Según acabamos de ver, y no obstante sus frecuentes cruzamientos, Canis lupus y Canis latrans deben ser consideradas como especies diferentes en virtud de que ellas configuran linajes evolutivamente autónomos: he ahí una idea que es central en el concepto evolutivo de especie propuesto por Simpson en $1951 .{ }^{23}$ De acuerdo con él, una especie es: "un linaje filético (una secuencia ancestro-descendiente de populaciones cruzables) que evoluciona independientemente de los otros linajes, y tiene un

Principia 17(3): 395-418 (2013). 
papel evolutivo separado y unitario, con sus propias tendencias" (Simpson: 1951, 289; 1961, p.153). Eso haría, según el propio Simpson dice a continuación, que la especie sea la unidad básica de los procesos evolutivos.

Pero, en la literatura contemporánea, ${ }^{24}$ la presentación de ese concepto más considerada es la enunciada por Edward Wiley; ${ }^{25}$ quien, de todos modos, siempre remite a Simpson como siendo su proponente original. ${ }^{26}$ Conforme la formulación de Wiley ([1978], p.80; 1981, p.25): "una especie evolucionaria es un linaje único de poblaciones ancestro-descendientes que mantiene su identidad en relación a otros linajes semejantes y que tiene sus propias tendencias evolutivas y su propio destino histórico". ${ }^{27}$ Canis lupus y Canis latrans, podemos decir ahora, son especies diferentes porque son dos linajes de poblaciones que tienen sus propias tendencias evolutivas y su propio destino histórico.

Si es cierto que eso ya insinúa una justificación a la distinción entre linajes de poblaciones aun entrecruzables; tampoco deja de ser cierto que hemos perdido bastante en precisión y claridad. La intensión de este concepto está menos delimitada que la intensión del concepto biológico (cf. Duchesneau 1997, p.31); y el problema está, justamente, en que no sabemos muy bien qué se quiere decir con expresiones destino histórico y tendencias evolutivas (Templeton 1992, p.160; Coyne \& Orr 2004, p.457), sobre todo cuando se dice que son propias de cada linaje. Uno se pregunta, por ejemplo: $i$ hay un destino propio de Canis lupus que sea común al dingo y al lobo mexicano? ¿ Y si digo que Canis lupus y Canis latrans no son de las misma especie porque están afectadas por tendencias evolutivas diferentes, no tendría que decir lo mismo del dingo y el lobo mexicano?

La idea de una división conceptual del trabajo (Richards 2010, p.119 y ss) no puede resolver esa dificultad: los criterios para identificar un tipo de entidad no pueden funcionar, ni siquiera existir, sin una idea clara de lo qué esa entidad sea. Y si mal o bien el concepto biológico especie cumplía ese servicio, el concepto evolutivo dejó de hacerlo. Aunque la idea de especie que nos da el concepto biológico presenta el importante defecto de ser demasiado restrictiva, nadie puede negarle claridad. Virtud ésta que el concepto evolutivo no tiene. Leight Van Valen (1992 [1976], p.69) ya había entrevisto esa dificultad en la definición de Simpson, y por eso se propuso mejorarla enunciando lo que se dio en llamar concepto ecológico de especie. ${ }^{28}$

Según dicho concepto: "una especie es un linaje (o un conjunto de linajes estrechamente relacionados) que ocupa una zona adaptativa mínimamente diferente de la zona ocupada por cualquier otro linaje en su rango y que evoluciona separadamente de todos los linajes ajenos a ese rango" (Van Valen 1992 [1976], p.70). ${ }^{29}$ Una especie, podríamos entonces decir, se define por la ocupación de un nicho ecológico específico: lo que distingue al coyote del lobo con el cual eventualmente se cruza, es el nicho ecológico que ocupan las poblaciones de uno y de otro. Por eso, un cachorro de padre lobo que lleve la vida de coyote de su madre, será coyote por eso; y 
no por su genoma híbrido. Es de esa vida de coyote, además, que se desprenden las presiones selectivas que marcan el destino propio del linaje coyote y lo distinguen del linaje lobuno. Pero es ya en ese punto que algunos autores han creído encontrar una dificultad en el concepto ecológico de especie.

Para muchos, poblaciones de lo que consideramos ser, claramente, especies diferentes pueden ocupar un mismo nicho y competir por él. ${ }^{30}$ Se dice que en algunas áreas de la Patagonia, la mara fue desplazada por la liebre europea, que va ocupando el nicho ecológico en el que aquélla medraba; y, de hecho, la propia idea de exclusión competitiva exige esa posibilidad (cf. Gause 1934). Para que una de las poblaciones de especies diferentes que compiten por un mismo nicho se extinga, es necesario justamente eso: que ellas compitan por un mismo nicho (Brewer 1994, p.231). Así, aunque el propio principio de exclusión competitiva nos haga pensar que la superposición de dos especies diferentes en un mismo nicho es un hecho poco común; es el mismo principio el que asume que esa situación puede darse, resultando, o en la extinción de una de las poblaciones, o en el desplazamiento de una de ellas hacia otro nicho. Y nadie querría decir que las poblaciones patagónicas de las libres europeas de la Patagonia y las maras, son parte de la misma especie.

Pero claro, una crítica de esa naturaleza parece más un argumento ad hominen que un argumento ad rem: ella apunta menos al propio concepto ecológico de especie que a la formulación quizá un poco descuidada que Van Valen le dio. ${ }^{31}$ Se diría que es una chicana. La misma, además, puede ser fácilmente respondida apelando para lo que se conoce como el 'cohesion species concept', propuesto por Alan Templeton (1992). De acuerdo con él, una especie es: "el grupo más inclusivo de organismos dentro del cual puedan existir intercambio genético y demográfico" (Templeton 1992, p.168).

Este concepto, se aparta del elemento evolutivo presente en la formulación de Van Valen: no alude a linajes y retoma la idea de intercambio genético subrayada por el concepto biológico de especie (Templeton 1992, p.171). Pero hace eso sin dejar de aludir a la identidad ecológica: ella se hace presente en la idea de intercambio (o equivalencia) demográfico (Templeton 1998, p.39). En este sentido, el concepto de Templeton puede ser considerado como una aproximación entre los conceptos ecológico y biológico (Sterelny \& Griffiths 1999, p.193); y su recurso a la idea de intercambio genético permite responder a la objeción de la mara y la liebre: poblaciones de mara y liebre que se superponen en un único nicho no son de la misma especie porque no existe intercambio genético entre ellas.

Creo, por otra parte, que no sería muy difícil reformular esa definición de Templeton, de manera tal que ella, aludiendo a linajes de organismos, y no simplemente a organismos, también incorpore el aspecto evolutivo de la especie, que es contemplado en la definición ecológica de Van Valen. Pero, hasta se podría argüir que el recurso a Templeton no es necesario. Cabría intentar salvar la supuesta dificultad 
suscitada por la posible superposición de dos especies en un mismo nicho ecológico, recurriendo a la idea de que tales nichos son construcciones de los propios seres vivos (Lewontin: 1979, p.143; 2001[1983], p.64); y que difícilmente nos vamos a encontrar con el caso de dos especies diferentes que construyan el mismo nicho. A lo sumo podremos encontrarnos con dos poblaciones de especies diferentes que, en virtud de sus respectivas y peculiares estrategias de vida, no encuentran cómo prescindir de un mismo recurso que escasea en la región por ellas habitada; y así entran en una competición que acaba en la extinción de una de ellas. Pero ahí no habría un mismo nicho y la situación no redundaría en ninguna dificultad para el concepto de especie formulado por Van Valen.

Pienso, sin embargo, que esa línea de argumentación no estaría atendiendo a la verdadera y más seria dificultad del concepto ecológico de especie. Aludo a la suposición, señalada recientemente por Diéguez (2012, p.225), de que cada especie ocupa un único nicho ecológico. Es decir: el verdadero problema no está en que dos especies puedan ocupar el mismo nicho: a esa dificultad, de ser real, se podría responder, como acabamos de ver, completando el concepto ecológico con alguna referencia al flujo de genes entre las poblaciones. El problema, que a Mayr (1982, p.275) no se le pasó por alto, está en pensar que una misma especie sólo ocupa un único nicho, un único lugar en la economía de la naturaleza; quedando así sometida a un régimen selectivo homogéneo que definiría, unitariamente, su destino evolutivo. Y esa dificultad, que aqueja tanto al concepto de Van Valen como al de de Templeton (1992, p.170-4), nos impide usarlos para mejor delimitar el concepto evolutivo de especie.

Conforme Niles Eldredge (1985, p.158-9) puntualizó ya hace muchos años: "salvo que una especie se restrinja a una única población, es imposible ir a la naturaleza, escoger una especie, y verla como un interactor en el plano ecológico. Por eso, desde el punto de vista económico, las especies parecen ser demasiado difusas como para desempeñar un rol particular. En un sentido puramente ecológico, económico, energético, las especies no existen" (cf. Caponi: 2011, p.29; 2012, p.248). Y la razón de ello es relativamente fácil de explicar:

Las especies no pueden ser miembros de un ecosistema local simplemente porque, típicamente, ellas están compuestas de múltiples poblaciones cuasiindependientes. Esas poblaciones locales están poco conectadas entre sí y se encuentran integradas en diferentes ecosistemas locales. El coyote norteamericano, Canis latrans, es un predador superior en los desiertos del sudoeste de los Estados Unidos, donde él depreda roedores, liebres, y otros miembros menores de la fauna de esa región. En el noreste de los Estados Unidos, los coyotes son habitantes del bosque, que comen pequeñas presas (capturando ocasionalmente algún ciervo de cola blanca), pero esas presas son de especies completamente diferentes a las cazadas por sus parientes de los desiertos del sudoeste. (Eldredge 1996, p.188). ${ }^{32}$

Principia 17(3): 395-418 (2013). 
No cabe desestimar la importancia de ese hecho diciendo que, pese a la variedad de las especies depredadas, ambas poblaciones de coyotes ocupan lugares análogos en sus respectivos ecosistemas; y que por eso puede decirse que coyotes del bosque y coyotes del desierto ocupan un mismo nicho. Difícilmente presas diferentes (de ecologías y comportamientos también diferentes), y entornos tan distintos como el de un bosque y el de un desierto, puedan redundar en condiciones ecológicas y en regímenes selectivos que puedan considerarse equivalentes. Si ahí se habla de un mismo nicho ecológico y de presiones selectivas equivalentes, ambos conceptos estarían siendo usados en un sentido tan vago y amplio que les quitaría todo contenido informativo. Las especies, tenemos que concordar con Eldredge (1996, p.189), "no tienen nichos". Las que sí tienen nichos son las poblaciones locales de esas especies que ocupan, o han generado, un lugar específico dentro de un ecosistema. Por eso no es posible recurrir a las nociones de nicho o de régimen selectivo, para en base a ellas, delimitar la elusiva noción de especie.

Lo que vale para los coyotes, además, vale más claramente todavía para subespecies de Canis lupus, como Canis lupus lupus, el lobo europeo de los inviernos nevados, y el Canis lupus dingo que supo abrirse especio en Australia. Pero en ambos casos la situación es análoga: ni el dingo está sometido a las mismas presiones selectivas que el lobo europeo, ni el coyote norteño está sometido a las mismas presiones selectivas del coyote sureño. La idea de subespecie siempre ha estado asociada con las exigencias y las oportunidades planteadas por ecologías diferentes (Stebbins 1966, p.86-7). No pocas de las diferencias entre subespecies obedecen a las presiones selectivas divergentes que esas ecologías diferentes posibilitan. Si los mapas de distribución de subespecies pueden coincidir con los mapas ecológicos, lo cierto es que "los mapas de la distribución de las especies no coinciden con los mapas de de la distribución de los ecosistemas" (Eldredge 1996, p.188).

\section{El concepto microevolutivo de especie}

Creo, sin embargo, que el concepto evolutivo de especie se puede salvar con relativa facilidad; y junto con él también se pueden rescatar los aspectos más importantes de los conceptos biológico y ecológico de especie. Ésos que Templeton quiso aunar en una única noción. Estos últimos conceptos, al igual que conceptos tipológicos de especie basados en semejanzas morfológicas o genéticas (cf. Sterelny \& Griffiths 1999, p.193), e incluso los conceptos filogenéticos (cf. Grene \& Depew 2004, p.298), podrán ser considerados como criterios eventualmente relevantes para determinar si un conjunto de poblaciones puede, o no, ser adscripto a un linaje de poblaciones entre las que nunca se llegó a establecer un aislamiento microevolutivo. Esta última es, conforme ya lo dije en la presentación, la delimitación del concepto de especie que 
quiero proponer; y notas como aislamiento reproductivo, subordinación a un mismo régimen selectivo, y semejanza morfológica, podrán ser consideradas como índices, relevantes en algunos casos pero no en otros y nunca por sí mismos decisivos, para la identificación y delimitación de linajes de poblaciones que merezcan contar como especies. ${ }^{33}$ He ahí, otra vez, mi compromiso con el pluralismo jerárquico de Mayden (2002, p.184-6): ese que Richards (2007, p.219-21) describió como una división conceptual del trabajo.

Para ver cuál es la supuesta ventaja de esa delimitación del concepto de especie que propongo, y para entender cómo es que ella puede superar las dificultades que invalidan a las otras propuestas, es necesario definir lo que ha de entenderse por aislamiento microevolutivo; y eso puede hacerse diciendo que: dos poblaciones están microevolutivamente aisladas; si y sólo si, los procesos microevolutivos que afectan a una de ellas (a saber: selección natural, deriva genética, selección sexual, mutación y/o migración), no pueden extenderse a la otra. La idea de que las especies son linajes de poblaciones microevolutivamente conectadas le da así un significado más preciso, más acotado, a esa referencia a un destino evolutivo común que encontramos en el concepto evolucionista de especie. Y lo mismo ocurre con la idea de que la especie es la unidad básica de los procesos evolutivos. Pero, pese a ese incremento en precisión, la definición propuesta no pierde generalidad.

En primer lugar, ella contempla la dimensión histórica de las especies: si en un linaje de seres vivos cualesquiera, una población actual $P^{3}$ deriva de una población ancestral $P^{2}$, hoy extinta y que no estaba microevolutivamente aislada de otra población $P^{1}$, hoy también extinta; entonces puede decirse que $P^{1}$ integró la misma especie que hoy integra $P^{3}$. Y ella también contempla la dispersión ecológica de las especies apuntada por Eldredge: dos poblaciones pueden integrar la misma especie aun cuando estén sometidas a presiones selectivas diferentes. Si existe alguna posibilidad, aunque remota, de que la presión selectiva que modifica la frecuencia relativa de dos alelos dentro de una población, pueda venir a modificar la frecuencia de esos mismos alelos en otra población de la cual la primera está muy aislada geográficamente, y ocupando un nicho ecológico diferente; entonces habrá que considerar que esas dos poblaciones todavía son parte de una misma especie. Lo mismo vale, además, para procesos de deriva génica y para procesos migratorios.

Pero esa posibilidad que una presión selectiva tiene de repercutir, indirectamente, en otras poblaciones de la misma especie sobre las que, sin embargo, ella no está, en sentido estricto, actuando, es esencial para entender la idea de aislamiento microevolutivo. Cuando esa repercusión no es posible, o es demasiado tenue y efímera, se puede hablar de aislamiento selectivo: uno de los índices más claros y significativos del aislamiento microevolutivo. Es importante, sin embargo, que no se confunda ese aislamiento selectivo con la adscripción a un mismo y único nicho ecológico: condición que, conforme ya vimos, entra en conflicto con la dispersión ecológica de las 
especies ya apuntada por Eldredge. Un ejemplo de manual, relativo a nuestra propia especie, puede ayudarnos a entender de qué estoy hablando. Aludo a aquel célebre alelo fatídico que, en homozigosis genera anemia falciforme extrema y mortal, pero en heterozigosis genera resistencia a la malaria.

Como se sabe, en ciertas poblaciones de África ese alelo es común pese a la inviabilidad que puede generar; y eso es así en virtud de que la alta incidencia de la malaria que se da en las regiones ocupadas por esas poblaciones. La malaria opera ahí como una presión selectiva favorable a ese alelo: no por lo que él hace en sus homocigotos; sino por la ventaja que le confiere a sus heterocigotos (Baker \& Allen 1970, p.509-11). Pero, aunque esa presión sólo opera en ciertas poblaciones, el sostenimiento en ellas de una frecuencia relativamente alta de ese alelo, siempre repercute en otras poblaciones no sometidas a la presencia de la malaria. Premiado donde abunda el mosquito que transmite el plasmodio responsable de la malaria, ese alelo infiltra otras poblaciones de Homo sapiens. Aunque en ellas la presión en su contra no se vea jamás compensada por ninguna ventaja de los heterocigotos. En esas poblaciones infiltradas dicho alelo tendrá una frecuencia quizá ínfima, pero siempre mayor a la que tendría si él no fuese premiado en otras regiones.

Se dirá, no sin alguna razón, que mi ejemplo no es muy significativo; porque lo posibilita esa infiltración es la propia ausencia de aislamiento reproductivo. Es esa ausencia la que permite que la presión selectiva sufrida por una población repercuta en otra que no la sufre. Por lo general, en las especies de reproducción sexuada la extensión del concepto de aislamiento selectivo coincide con la extensión del concepto de aislamiento reproductivo. Poblaciones de organismos sexuados de las que podemos estar seguros que no están reproductivamente aisladas, están, con la misma seguridad, selectivamente vinculadas y, por eso, microevolutivamente conectadas. Los efectos de las presiones selectivas que ocurren en una de ellas siempre podrán repercutir, en mayor o menor grado, en las otras; valiendo lo mismo para efectos fundadores y deriva génica. Por eso el aislamiento reproductivo es un excelente criterio, nadie lo duda, para distinguir especies de organismos sexuados (cf. Stebbins 1966, p.86; Grant 1986, p.51).

Tal es así que, si dudamos de la conectividad reproductiva de dos poblaciones que, por otros criterios, podríamos suponer como integrantes de una misma especie de reproducción sexuada, ahí también dudaremos de su conexión selectiva y, consecuentemente, también dudaremos de su conexión microevolutiva: dudaremos de considerarlas como partes de la misma especie. Pero esa coincidencia entre la extensión de los conceptos de aislamiento reproductivo y microevolutivo no se cumple, claro, cuando hablamos de organismos de reproducción asexuada. Allí la idea de aislamiento reproductivo no se aplica; pero sí se aplica la de aislamiento selectivo. Y con ella la de aislamiento microevolutivo. Quedando claro, entonces, que el concepto microevolutivo de especie, no tiene la misma intensión que el concepto biológico. 
Es de apuntarse, por otro lado, que aun no existiendo barreras fisiológicas o etológicas para el cruzamiento fértil entre los individuos de ambas poblaciones, si el aislamiento geográfico es lo suficientemente pronunciado como para imposibilitar que las presiones selectivas, los procesos de deriva génica o de migración que afectan a una, afecten alguna vez, de algún modo, a la otra; entonces, en ese caso, tendremos que considerar la posibilidad de estar ante especies diferentes. Canis lupus dingo podría estar en esa situación respecto del resto de Canis lupus; aunque, como veremos después, puede haber otras consideraciones a hacer, que nos llevarían a seguir tratando al dingo como siendo una subespecie de lobo. Quizá deberíamos considerar que, en casos como eses, estamos ante especies incipientes: especies cuyos procesos de especiación aun no se han completado plenamente y por eso aun no son totalmente irreversibles; ${ }^{34}$ habiendo, claro, distintos grados de reversibilidad en lo atinente a eso.

Equus caballus y Equus asinus designan, en este sentido, dos conjuntos de poblaciones más microevolutivamente aisladas entre ellas, que aquellas designadas por Canis lupus y Canis latrans. Aun cuando, en ambos casos, estemos hablando, hasta donde sabemos, de especies diferentes. La especiación, ya lo vimos, es un proceso natural, paulatino, que puede haber avanzado más o menos; y no tiene nada de extraño que el concepto de especie refleje esa condición. Conforme afirmó recientemente Geoffrey Chambers (2012, p.760): “(1) La identificación de una especie es relativa, (2) dependiente de los datos disponibles y de inferencias razonables y (3) forzada a abarcar procesos de especiación que son generalmente graduales". Lo extraño sería lo contrario: que la delimitación de especies fuese una demarcación clara, límpida y taxativa como una distinción de razón.

Pero ahora prefiero insistir en esto: el aislamiento reproductivo no es una nota esencial del aislamiento microevolutivo; ni siquiera en el caso de las especies de reproducción sexuada. El aislamiento reproductivo, de existir en algún grado, puede indicarnos hasta qué punto se ha consumado el aislamiento microevolutivo; pero se puede hablar de aislamiento microevolutivo sin que haya aislamiento reproductivo: el aislamiento puramente geográfico, como acabo de decir, puede ser causa suficiente de aislamiento microevolutivo. Y el hecho de que en esos casos la alopatría pueda revertirse, posibilitando lo que entonces tendría que ser considerado como la fusión de dos especies, no configura un argumento contrario a lo que estoy diciendo: las especies se pueden fundir, sí (cf. Grant \& Grant 2008, p.116). Decir que la especiación es un proceso reversible ya es, por otra parte, una forma de asumirlo; y el reconocimiento de que existe especiación por hibridación nos indica que no hay nada de escandaloso en esa idea. ${ }^{35}$

Es, por otra parte, esa misma reversibilidad de la especiación la que nos impide de definir la noción de especie apelando a un aislamiento microevolutivo irreversible. Si por la razón que fuere una especie queda divida en dos linajes que entran 
en perfecto aislamiento microevolutivo, y en esa condición permanecen a lo largo de varias generaciones, diremos que ellos han constituido dos especies diferentes y así lo consideraremos hasta que esa aislamiento se termine - si es que eso ocurre, claro-generándose una fusión entre las dos especies (cf. De Queiroz, 2003, p.207). Fusión que, ya lo vimos, es considerada como una nueva especiación: ${ }^{36}$ como el origen de una especie que antes no existía. Mientras hay aislamiento microevolutivo, hay dos especies; y cuando deja de haberlo pasa a ver una nueva especie surgida por hibridación. No es necesario suponer que el aislamiento microevolutivo sea irreversible para hablar de dos especies diferentes; y la propia idea de especiación por hibridación trae con ella la suposición de que esa reversión puede existir.

\section{Bacterias, lobos y coyotes}

Pero el hecho de que el aislamiento reproductivo no sea una nota esencial del aislamiento microevolutivo, tiene otras consecuencias que también merecen ser apuntadas. La más obvia tiene que ver con el problema suscitado por los organismos de reproducción asexuada. La misma razón que hace que el aislamiento reproductivo sea demasiado estrecho como definiens de especie, también hace que sea inaplicable como criterio para delimitar el aislamiento microevolutivo de las poblaciones de tales organismos. Pero eso sí puede hacerse recurriendo a la idea aislamiento selectivo. En las especies de reproducción asexuada, el aislamiento selectivo puede diagnosticarse apelando a lo que, siguiendo a Coyne y a Orr podemos denominar 'reemplazo de clones'. Según estos autores:

La aparición de una nueva mutación adaptativa en una población de bacterias, produce un evento momentáneo de selección, durante el cual el clon mutante reemplaza todos los otros clones que tienen propiedades ecológicas semejantes. Tal reemplazo puede también ocurrir por intermedio del equivalente asexual de la deriva genética: diferencias azarosas en los índices de reproducción entre clones demográficamente intercambiables (Coyne \& Orr 2004, p.454).

Así, y conforme ellos mismos lo sugieren, en casos donde no quepa hablar de ese reemplazo de clones, consideraremos que estamos ante especies diferentes. Si existen dos cepas de un mismo linaje de bacterias que pululan en un mismo hábitat, pero el crecimiento de un clon dentro de una de ellas, no redunda en la disminución de ninguno de los clones de la otra, diremos que se trata de dos especies diferentes. Mientras tanto, si esas dos cepas pululan en hábitats diferentes, pero tenemos razones para pensar que, en caso de revertirse esa situación, dicho reemplazo de clones habría de ocurrir, ahí diríamos que se trata de linajes de la misma especie. Los procesos de deriva genética, o las presiones selectivas, que actúan sobre una de 
esas cepas, pueden aun afectar a la otra cepa. Las mismas no están selectivamente aisladas: no están microevolutivamente aisladas; y por eso decimos que integran la misma especie bacteriana.

Es verdad, por otro lado, que el reemplazo supuestamente intra-especifico de un clon por otro, puede no ser muy fácil de distinguir de un fenómeno inter-especifico de exclusión competitiva. Pero ahí, me parece, pueden entrar a tallar criterios de otra índole. Si los linajes en pugna guardan mayor semejanza genética entre sí que aquella que ellos mismos guardan con cualquier otro linaje que medra en otras condiciones ecológicas, estaremos inclinados a pensar que estamos ante un caso de reemplazo de un clon por otro al interior de una misma especie. En cambio, si los linajes en pugna son muy diferentes, y para cada uno de ellos somos capaces de apuntar linajes genéticamente más cercanos, estaremos inclinados a tratarlos como especies distintas. En organismos de reproducción asexuada, los criterios tipológicos para distinguir especies son inevitables (cf. Ayala 2005, p.20). Pero esos criterios también suelen ser inevitables en Paleontología (Simpson 1951, p.290). Lo importante es no confundir criterios para identificar especies con definiciones de lo qué las especies son. La definición es una; los criterios, varios.

En organismos de reproducción asexuada, podemos decirlo siguiendo al propio Mayr (2001, p.173), la especiación ocurre como efecto de la separación ecológica que la selección natural va produciendo entre linajes sometidos a condiciones de vida divergentes (Mayr, 2007[1963] p.212); y si ese reconocimiento puede no darse del todo bien con el concepto biológico de especie, el mismo no tiene porque entrar en conflicto con el concepto microevolutivo de especie que estoy intentando delinear: esa separación ecológica es la primera responsable del aislamiento selectivo. Dos cepas de un mismo linaje pueden acabar medrando en ambientes tan distintos, o dependiendo se recursos tan diferenciados, que el éxito de un clon dentro de una de ellas, que desplaza y deja sin espacio a los otros clones de su mismo clan, en poco afecta a los clones del otro clan; que siguen compitiendo entre ellos mismos. El principio de divergencia (Darwin 1859, p.112) vale para las bacterias; ${ }^{37}$ y la dispersión en diferentes nichos ecológicos que esa divergencia produce puede también ayudarnos a individualizar especies.

Esa última idea sirve, además, para darle un sentido más claro a la idea de que el coyote y el lobo, pese a sus recurrentes hibridaciones, se comporten como linajes evolutivamente independientes. Lobo y coyote son linajes entre los que ocurre una cierta transferencia lateral de genes, pero las presiones selectivas a las que están sometidos los mantienen microevolutivamente separados; como suelen mantenerse microevolutivamente separados los linajes de bacterias en los que también ocurre esa transferencia lateral de genes. La misma selección natural que alguna vez separó los linajes, hoy los mantiene separados, porque en general, lo que sirve para ser coyote, no sirve para ser lobo. Es decir: las mismas presiones selectivas que modelan a 
los coyotes son las que levantan el muro de aislamiento selectivo que los separa de los lobos: lo que ayuda entre lobos suele estorbar entre coyotes; y eso conspira contra la repercusión entre los coyotes de las presiones selectivas actuantes entre los lobos. Aun cuando existan eventuales cruzamientos entre ellos.

No se trata ya de un único alelo, como aquel de la anemia falciforme, que pasa de una población que padece malaria a otra que no la padece, pero lo hace envuelto en toda una constelación de características perfectamente compatibles con ambas ecologías. Se trata de todo una constelación de particularidades morfológicas, fisiológicas y etológicas que, según se supone, responden, globalmente, a las diferentes ecologías de ambos linajes. Siendo esas mismas diferencias ecológicas las que van a impedir que, pese a la imperfección del aislamiento reproductivo, las presiones selectivas que modelan a las poblaciones de coyote afecten significativamente a las de lobo. El aislamiento selectivo puede levantar barreras donde el aislamiento reproductivo no las levantó, castigando con el escaso éxito reproductivo a todo aquello que pueda anular la diferencia entre linajes.

Distinto es lo que ocurre, según parece suponerse, entre dingos y lobos mexicanos. Ahí las diferencias también son efecto, se diría, de las presiones selectivas divergentes a las que quedan sometidos linajes que exploran y explotan ecosistemas distintos. Además, claro, de la incidencia de procesos de deriva genética, o resultantes del efecto fundador, que también pudieron producir, y seguramente produjeron, una gran parte de la divergencia de caracteres que allí puede percibirse. Pero, en ese caso, la divergencia ecológica parece haber sido producida por la simple separación geográfica. La separación geográfica redundó en la explotación de ambientes diferentes; y eso, a su vez, resultó en presiones selectivas también diferentes. En el caso de lobos y coyotes es la propia selección natural la que, por mor del principio de divergencia, premia la separación ecológica; en el dingo y el lobo mexicano es la separación ecológica la que redunda en presiones selectivas diferentes y divergentes.

Por eso podemos suponer que en el caso del coyote y el lobo hay todo un complejo de presiones selectivas 'anti-convergencia' que no existe en el cado de dingos y lobos mexicanos. No existen porque no hacen falta. Y eso también nos lleva a pensar que, pese a estar geográficamente más separadas entre sí que lobos mexicanos y coyotes, esas dos subespecies de Canis lupus podrían reconectarse selectivamente, aunque sea indirectamente - por la mediación de otras subespecies —; o incluso entrecruzarse con relativa facilidad, generando híbridos ecológicamente viables. Como ya ocurrió, dicho sea de paso, entre los Homo sapiens de América y aquellos otros que llegaron a estas playas, desde África y Europa, después del primer viaje de Colón. Dingo y lobo mexicano, pensamos, no son aun linajes de poblaciones que estén microevolutivamente aisladas; y pensamos eso porque creemos que, además de no existir barreras reproductivas entre ellos, barreras a la Mayr, tampoco los separan barreras selectivas demasiado significativas y poderosas como las que suponemos 
que existen entre los coyotes y los lobos.

Es claro, sin embargo, que aun estas últimas barreras selectivas podrían llegar a erosionarse. Como pueden erosionarse esas barreras que posibilitan el aislamiento reproductivo. Eso podría permitir una fusión de especies: una especiación por hibridación. Pero mientras supongamos la existencia de tales barreras selectivas, seguiremos hablando de dos especies; y sería la propia suposición de que existen dos especies, la que después nos permitiría hablar de una especiación por hibridación. Cosa que nunca nos permitiríamos si lo que está en juego es la fusión de dos subespecies dentro de una misma especie. Allí no tendríamos razón para hablar de especiación por hibridación.

\section{Para terminar}

No se puede negar, de todos modos, que todas las suposiciones que nos llevarían a trazar esas distinciones que acabo de hacer, no podrían ser otra cosa que hipótesis empíricas y falibles: conjeturas más o menos razonables. Pero no hay escapatoria: delimitar especies es formular hipótesis plausibles, y siempre rectificables, sobre fenómenos naturales. Tal como ocurre con el resto de nuestro conocimiento científico. Aunque no lo sepamos, el dingo quizá ya esté demasiado lejos evolutivamente de los lobos mexicanos: tal vez la separación entre ellos no sea mucho menor que aquella que separa a esos mismos lobos de sus vecinos coyotes. Pero eso no importa aquí: lo que sí importa es que el concepto microevolutivo de especie parece darle una razón al hecho de que, por ahora, el dingo y el lobo mexicano sean considerados parte de la misma especie, cuando este último y el coyote no lo son. Eso es lo que cuenta en el análisis filosófico: elucidar la gramática de nuestros conceptos de forma tal que, en sus reglas de uso, se puedan encontrar las claves para superar, o aclarar, las perplejidades a las que ese mismo uso suele conducir.

\section{Referencias}

Adams, B. 1998. Species concepts and the evolutionary paradigm in modern nematology. Journal of Nematology 30(1): 1-21.

Agustí, J. 2003. Fósiles, genes y teorías. Barcelona: Tusquets.

Allano, L.; Clamens, A. 2010. Faits et mécanismes de l'évolution biologique. Paris: Ellipses.

Arias, D.; Riesenberg, L.; Sinervo, B.; Linder, R.; Ungerer, M. 1997. Role of gene interactions in hybrid speciation. In: M. Ridley (ed.) Evolution. Oxford: Oxford University Press, p.189-82

Ayala, F. 2005. The evolution of organisms: a synopsis. In: F. Ayala; F. Wuketits (eds.) Handbook of evolution, Vol. II. New York: Wiley, p.1-26

Principia 17(3): 395-418 (2013). 
Baker, J.; Allen, G. 1970. Biología e investigación Científica. Bogotá: Fondo Educativo Latinoamericano.

Baum, D.; Donoghue, M. 2006[1995]. Choosing among alternative phylogenetic species concepts. In: E. Sober (ed.) Conceptual Issues in Evolutionary Biology. Cambridge: MIT Press, p.387-408

Boggs, C. 2001. Species and speciation. In: N. Smelser; P. Baltes (eds.) International Encyclopedia of the Social and Behavioral Sciences. Elsevier: Amsterdam, p.14.855-14.861

Brewer, R. 1994. The science of Ecology. New York: Saunders.

Brigandt, I. 2003. Species pluralism does not imply species eliminativism. Philosophy of Science 70: 1305-16.

Buffon, G. 1749. Histoire Naturelle générale et particulière, T.II. Paris: L'Imprimerie Royal.

Cain, A. 1970[1954]. Las especies animales y su evolución. Barcelona: Labor.

Caponi, G. 2010. Buffon. México: UAM.

- 2011. Los linajes biológicos como individuos. Ludus Vitalis 35: 17-48.

2012. Linajes y sistemas: dos tipos de individuos biológicos. Scientiae Studia 10(2): 243-68.

Chambers, G. 2012. The species problem: seeking new solutions for philosophers and biologist. Biology \& Philosophy 27: 755-65.

Chapman, M.; Burke, J. 2007. Genetic divergence and hybrid speciation. Evolution 61: 177380.

Claridge, M. 2010. Species are real biological entities. In: F. Ayala; R. Arp (eds.) Contemporary debates in Philosophy of Biology. Oxford: Wiley-Blackwell, p.91-109.

Coyne, J.; Orr, A. 2004. Speciation. Sunderland: Sinauer.

Cracraft, J. 1987. Species concept and the ontology of evolution. Biology \& Philosophy 2: 329-46.

Darwin, C. 1859. On the origin of species. London: Murray.

De Queiroz, K. 2003. A unified concept of species and its consequences for the future of Taxonomy. In: N. Jablonski (ed.) Proceeding of the Symposia: Biodiversity, Past, Present and Future \& The Future of Taxonomy, held in the occasion of the 150TH anniversary of the California Academy of Sciences. San Francisco: California Academy of Sciences, p.196-215

- 2007. Species concepts and species delimitation. Systematics Biology 56(6): 879-86.

- 2011. Branches in the lines of descent: Charles Darwin and the evolution of the species concept. Biological Journal of the Linnean Society 103: 19-35.

Delsol, M.; Gayon, J.; Le Guyader, H.; Lamotte, M.; Perru, O. 2002. Lévolution biologique: faits, théories, épistémologie, philosophie, Tome II. Paris: Vrin.

Diéguez, A. 2012. La vida bajo escrutinio. Barcelona: Buridán.

Dobzhansky, Th. 1935. A critique of the species concept in Biology. Philosophy of Science 2(3): 344-55.

-1951. Genetics and the origin of species, $3^{\text {rd }}$ edition. New York: Columbia University Press.

—. 1966[1955]. La evolución, la genética y el hombre. Buenos Aires: EUDEBA.

—. 1966[1962]. La idea de especie después de Darwin. In: S. Barnett (ed.) Un siglo después de Darwin, Vol. I. Madrid: Alianza, p.37-82.

Dobzhansky, Th; Ayala, F; Stebbins, G.; Valentine, J. 1980. Evolución. Barcelona: Omega.

Duchesneau, F. 1997. Philosophie de la Biologie. Paris: PUF.

Principia 17(3): 395-418 (2013). 
Dupré, J. 1992. Species: theoretical context. In: E. Fox Keller; E. Lloyd (eds.) Keywords in Evolutionary Biology. Cambridge: Harvard University Press, p.312-7.

Dykhuizen, D. 2003. Species numbers in Bacteria. In: N. Jablonski (ed.) Proceeding of the Symposia: Biodiversity, Past, Present and Future \& The Future of Taxonomy, held in the occasion of the 150TH anniversary of the California Academy of Sciences. San Francisco: California Academy of Sciences, p.62-71

Eldredge, N. 1985. Unfinished synthesis: biological hierarchies and modern evolutionary thought. Oxford: Oxford University Press.

- 1996. Reinventing Darwin. London: Phoenix.

Eldredge, N.; Cracraft, J. 1980. Phylogenetic patterns and the evolutionary process. New York: Columbia University Press.

Ereshefsky, M. 1992. Eliminative pluralism. Philosophy of Science 59(4): 671-90.

- 2004. The poverty of the linnaean hierarchy. Cambridge: Cambridge University Press.

- 2010. Darwin's solution to the species problem. Synthese 175: 405-25.

Freire-Maia, N. 1988. De Darwin à teoria sintética. São Paulo: EDUSP.

Flourens, P. 1850. Histoire des travaux et des idées de Buffon. Paris: Hachette.

- 1861. Ontologie Naturelle. Paris: Garnier.

- 1864. Examen du livre de M. Darwin sur l'origine des espèces. Paris: Garnier.

Futuyma, D. 2005. Evolution. Sunderland: Sinauer.

Gause, G. 1934. The struggle for existence. Philadelphia: Williams \& Wilkins Company.

Génermont, J. 1998. Qu'est-ce qu'une espèce? In: H. Le Guyader (ed.) L'évolution. Paris: Pour la Science, p.36-9.

Ghiselin, M. 1997. Metaphysics and the origin of species. Albany: SUNY Press.

González, F. 2011. O problema da espécie 150 años depois de A Origen. In: P. Abrantes (ed.) Filosofia da Biologia. Porto Alegre: Artmed, p.97-123

Grant, P. 1986. Ecology and evolution of Darwin's finches. Princeton: Princeton University Press.

Grant, P.; Grant, R. 2008. How and why species multiply: the radiation of Darwin's finches. Princeton: Princeton University Press.

Grant, V. 1997[1981]. Hybrid speciation. In: M. Ridley (ed.) Evolution. Oxford: Oxford University Press, p.186-9.

Grene, M.; Depew, D. 2004. The Philosophy of Biology. Cambridge: Cambridge University Press.

Hennig, W. 1968. Elementos de una sistemática filogenética. Buenos Aires: EUDEBA.

Huxley, J. 1940. Towards the new Systematics. In: J. Huxley (ed.) The new Systematics. Oxford: Clarendon Press, p.1-46

- 1963[1943]. Evolución: la síntesis moderna. Losada: Buenos Aires.

Huxley, T. 1893[1859]. The darwinian hypothesis. In: T. Huxley, Darwiniana. New York: Appleton, p.1-21

Lack, D. 1947. Darwin's finches. Cambridge: Cambridge University Press.

Lalande, A. 1947. Vocabulaire technique et critique de la philosophie. Paris: PUF.

Laporte, L. 1994. Simpson on species. Journal of History of Biology 27(1): 141-59.

Lewontin, R. 1979. La adaptación. In: Evolución. Barcelona: Libros de Investigación \& Ciencia, p.139-52.

Principia 17(3): 395-418 (2013). 
2001[1983]. Gene, organism and environment. In: S. Oyama; P. Griffiths; R. Gray (eds.) Cycles of contingency. Cambridge: MIT Press, p.59-66.

Mayden, R. 1999. Consilience and hierarchy of species concepts: advances toward closure on the species puzzle. Journal of Nematology 31(2): 95-116.

- 2002. On biological species, species concepts and individuals in the nature world. Fish \& Fisheries 3: 171-96.

Mayhew, P. 2006. Discovering Evolutionary Ecology. Oxford: Oxford University Press.

Maynard Smith, J. 1993. The theory of evolution. Cambridge: Cambridge University Press.

Mayr, E. 1942. Systematics and the origin of species. Cambridge: Harvard University Press. . 2007[1963]. Species concepts and their application. In: M. Ruse (ed.) Philosophy of Biology. Amherst: Prometheus, p.203-213

- 1982. The growth of biological thought. Cambridge: Harvard University Press.

- 1988. Toward a new Philosophy of Biology. Cambridge: Harvard University Press.

- 2000. The Biological Species Concept. In: Q. Wheeler; R. Meier (eds.) Species concepts and Phylogenetic Theory. New York: Columbia University Press, p.17-29.

. 2001. What evolution is. New York: Basic Books.

Meier, R.; Willmann, R. 2000. The hennigian Species Concept. In: Q. Wheeler; R. Meier (eds.) Species concepts and Phylogenetic Theory. New York: Columbia University Press, p.30-43.

Mishler, B. 2010. Species are not uniquely real biological entities. In: F. Ayala; R. Arp (eds.) Contemporary debates in Philosophy of Biology. Oxford: Wiley-Blackwell, p.110-22.

Mishler, B.; Donoghue, M. 1992[1982]. Species concept: a case for pluralism. In: M. Ereshefsky (ed.) The units of evolution. Cambridge: MIT Press, p.121-38.

Mishler, B.; Brandon, R. 1998[1987]. Individuality, pluralism, and the phylogenetic species concept. In: D. Hull; M. Ruse (eds.) Philosophy of Biology. Oxford: Oxford University Press, p.300-18.

Mishler, B.; Theriot, E. 2000. The Phylogenetic Species Concept (sensu Mishler and Theriot): monophyly, apomorphy, and phylogenetic species concepts. In: Q. Wheeler; R. Meier (eds.) Species concepts and Phylogenetic Theory. New York: Columbia University Press, p.44-54.

Lecointre, G. 2008. Comprendre et enseigner la classification du vivant. Paris: Belin.

Ledesma Mateos, I. 2000. Historia de la Biología. México: AGT.

Paterson, H. 1992. The recognition concept of species. In: M. Ereshefsky (ed.) The units of evolution. Cambridge: MIT Press, p.139-58

Richards, R. 2007. Solving the species problem: Kitcher and Hull on sets and individuals. In:

M. Ruse (ed.) Philosophy of Biology. Amherst: Prometheus, p.215-27.

- 2010. The species problem. Cambridge: Cambridge University Press.

Ridley, M. 1989. The cladistic solution to the species problem. Biology \& Philosophy 4: 1-16.

Samadi, S.; Barberousse, A. 2011. Espèce. In: T. Heams; Ph. Huneman; G. Lecointre; M.

Silberstein (eds.) Les mondes darwiniens. Paris: Éditions Matériologiques, p.243-70

Schopenhauer, A. 1996[1864, póstumo]. El arte de tener razón. Madrid: Edaf.

Simpson, G. 1951. The species concept. Evolution 5(4): 285-98.

-1961. Principles of animal taxonomy. New York: Columbia University Press.

Stebbins, G. 1966. Processes of organic evolution. Englewood Cliffs: Prentice-Hall.

Sterelny, K.; Griffiths, P. 1999. Sex and Death. Chicago: Chicago University Press.

Principia 17(3): 395-418 (2013). 
Strickberger, M. 1976. Genética. Barcelona: Omega.

Templeton, A. 1992. The meaning of species and speciation: a genetic perspective. In: M. Ereshefsky (ed.) The units of evolution. Cambridge: MIT Press, p.159-83

- 1998. Species and speciation: geography, population structure, ecology and gene trees. In: D. Howard; S. Berlocher (eds.) Endless forms: species and speciation. Oxford: Oxford University Press, p.32-43.

Van Valen, L. 1992[1976]. Ecological species, multispecies, and oaks. In: M. Ereshefsky (ed.) The units of evolution. Cambridge: MIT Press, p.69-78,

Videira, A. 2000. Para que servem as definições? In: A. Videira; C. El-Hani (eds.) O que é vida? Rio de Janeiro: Relume Dumará, p.17-30.

Volpe, P. 1967. Understanding evolution. Dubuque: Brown.

Wheeler, Q.; Platnick, N. 2000. The Phylogenetic Species Concept (sensu Wheeler \& Platnick). In: Q. Wheeler; R. Meier (eds.) Species concepts and Phylogenetic Theory. New York: Columbia University Press, p.55-69.

Wiley, E. 1992[1978]. The evolutionary species concept reconsidered. In: M. Ereshefsky (ed.) The units of evolution. Cambridge: MIT Press, p.79-92.

- 1981. Phylogenetics. New York: Wiley.

Wiley, E.; Mayden, R. 2000. The evolutionary species concept. In: Q. Wheeler; R. Meier (eds.) Species concepts and Phylogenetic Theory. New York: Columbia University Press, p.70-89.

Wiley, E.; Lieberman, B. 2011. Phylogenetics. Hoboken: Wiley-Blackwell.

Wilkins, J. 2009. Species: a history of the idea. Berkeley: University of California Press.

Williams, M. 1992. Species: current usages. In: E. Fox Keller; E. Lloyd (eds.) Keywords in Evolutionary Biology. Cambridge: Harvard University Press, p.318-23.

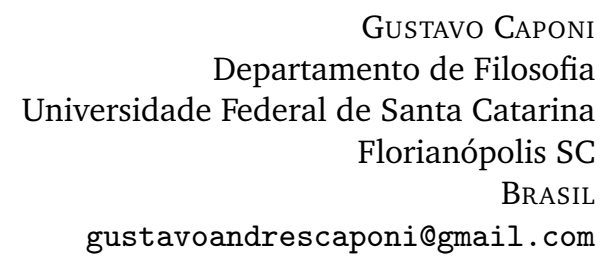

Resumo. Uma espécie pode ser definida como uma linhagem de populações entre as quais nunca chegou-se a establecer um isolamento micro-evolutivo; e o que se deve entender por isolamento micro-evolutivo é isto: duas populações estão micro-evolutivamente isoladas se, e somente se, os processos micro-evolutivos que afetam uma delas (a saber: seleção natural, deriva genética, seleção sexual, mutação e/ou migração), não podem estender-se à outra. Essa es uma delimitação do conceito evolucionário de espécie que es compatível, e solidária, com a divisão conceitual do trabalho que alguns autores propuseram como solução para o problema suscitado pela definição de espécie.

Palavras-chave: Isolamento micro-evolutivo; conceito evolucionário de espécie; definição de espécie.

Principia 17(3): 395-418 (2013). 


\section{Notas}

${ }^{1}$ Tomo ‘intensión' en el sentido de "conjunto de caracteres considerados como esenciales a una clase" (Lalande 1947, p.528).

${ }^{2}$ Ver también: Mishler \& Donoghue (1992[1982]); y Mishler \& Brandon (1998[1987]).

${ }^{3} \mathrm{Al}$ respecto, ver: Sterelny \& Griffiths (1999, p.193); Coyne \& Orr (2004, p.27); y Futuyma (2005, p.354).

${ }^{4}$ Sobre la utilidad teórica de las definiciones en general, véase: 'Para que servem as definições?', de Antonio Videira (2000).

${ }^{5}$ Esta idea ha sido también adoptada en la nueva edición de Phylogenetics (Wiley \& Lieberman, 2011, p.28-9), y reivindicada cum granus salis por Geoffrey Chambers (2012, p.759). Pero hay otros autores que también llegaron a posiciones semejantes. Tal el caso de Mark Ridley (1989), Byron Adams (1998) e Ingo Brigandt (2003). En Ridley, sin embargo, es una variante del concepto cladistico de especie, y no el concepto evolutivo de especie, que ocupa el lugar de articulador central.

${ }^{6}$ El concepto biológico de especie ya puede encontrarse en evolucionistas anteriores como Jordan y Poulton (cf. Mayr 1982, p.272; 2000, p.19); y también en naturalistas pre-evolucionistas como Ray y Buffon (Mayr, 1982, p.271; Ledesma Mateos, 2000, p.380; Allano \& Clamens 2010, p.47; Diéguez, 2012, p.220). Un entendimiento de la noción especie, y de la noción de género, de cuño no evolucionista aunque no pre-darwiniano, que también puede considerarse como precursor del moderno concepto biológico de especie, lo encontramos en la Ontologie Naturelle del cuvieriano tardío Pierre Flourens (1861 p.14-6). Ahí leemos: "la fecundidad continua da la especie; la fecundidad restringida da el género" (Flourens 1861, p.14); y la misma idea también es enunciada en el deplorable Examen du libre de $M$. Darwin sur l'origine des espèces que Flourens (1864, p.108) publicó poco después. Flourens era un lector asiduo de Buffon (cf. Flourens 1850); y es de la obra de ese naturalista (cf. Caponi 2010, p.86) que él deriva ese entendimiento biológico del género y de la especie (cf. Flourens: 1850, p.97; 1861, p.12). Thomas Huxley (1893[1859], p.3) apunta la esterilidad parcial o total de los híbridos, como el criterio clásico para distinguir especies; aunque rechace su validez general.

${ }^{7}$ Subrayase que, diferentemente de lo que ocurre en formulaciones suyas más primitivas, tal como la que encontramos en Buffon, esta definición biológica de especie no alude a individuos, sino que se refiere a poblaciones (Ghiselin 1997, p.95). Y esto puede generalizarse para cualquier concepto moderno de especie (Simpson 1951, p.287). Cosa que Diéguez (2012, p.221) pasa por alto cuando dice que el actual concepto biológico de especie falla por ser inaplicable a individuos estériles como las hormigas obreras. Lo que Buffon (1749, p.10-1) decía, recordémoslo, es que se debe considerar como siendo individuos de la misma especie a aquellos que "por la copulación" se perpetúan y conservan la similitud de esa especie, y como de especies diferentes a aquellos que, "por los mismos medios, no pueden producir nada juntos" (cf. Caponi 2010, p.85). Ahí sí estaríamos cayendo en la dificultad apuntada por Diéguez; pero no en el caso de Mayr.

${ }^{8} \mathrm{Al}$ respecto de esa importancia, ver: Freire-Maia (1988, p.196); Duchesneau (1997, p.21); Agustí (2003, p.84); Grene \& Depew (2004, p.293); Wilkins (2009, p.189); y Diéguez (2012, p.220).

Principia 17(3): 395-418 (2013). 
${ }^{9}$ El concepto de aislamiento reproductivo, siempre vale recordarlo, es muy amplio en lo que atañe a los mecanismos etológicos, fisiológicos, morfológicos y genéticos que son capaces de generarlo. Al respecto, ver: Dobzhansky (1966[1962], p.51); Stebbins (1966, p.97); Strickberger (1976, p.830); Dobzhansky et al, 1980, p.173; Templeton (1992, p.161); Ghiselin (1998, p.95); Boggs (2001, p.14.857); Coyne \& Orr (2004, p.27); Futuyma (2005, p.360); Allano \& Clamens (2010, p.49).

${ }^{10}$ Ese compromiso con el concepto biológico de especie se refuerza en el glosario de Evolución (Futuyma 2005, p.552). Y ciertamente que el concepto biológico de especie fue, y sigue siendo, el concepto más refrendado por manuales y glosarios: aquél al cual finalmente nos remitimos cuando queremos tener una pauta clara a partir de la cual seguir hablando de lo que realmente importa. Doy los ejemplos que tengo a mano: Stebbins (1966, p.86); Volpe (1967, p.83); Strickberger (1976, p.829); Dobzhansky et al (1980, p.197); Brewer (1994, p.758); Delsol et al. (2002, p.48); Ayala (2005, p.19); Lecointre (2008, p.341); y Grant \& Grant (2008, p.119). Creo que son significativos.

11 Véase: Wiley (1992[1978], p.86); Freire-Maia (1988, p.197); y Ereshefsky (2004, p.190).

12 Véase: Cain (1970[1954], p.94); Coyne \& Orr (2004, p.45); Ayala (2005, p.20); Futuyma (2005, p.357); y Allano \& Clamens (2010, p.49-50).

${ }^{13} \mathrm{Al}$ respecto, ver: Wiley (1992[1978], p.86); Dupré (1992, p.315); y Richards (2010, p.99). Dobzhansky (1966[1955], p.192) también formuló esa idea bajo la forma de un pluralismo discreto: "la especie en los organismos asexuales y autofecundados" - dijo — "no es el mismo fenómeno biológico que el de las especies de insectos, pájaros, mamíferos y plantas superiores de fertilización cruzada".

14 Para superar esta dificultad en lo que atañe al caso especial de las bacterias, pero respetando lo esencial del concepto biológico de especie, Daniel Dykhuizen (2003) propuso una definición de especie bacteriana que vendría a ser una variante, o la versión bacteriológica, de la definición biológica. Según la misma, una especie bacteriana sería "un grupo de individuos en donde la trasferencia lateral de genes observada dentro de ese grupo es mucho mayor que aquella observada entre otros grupos, de forma tal que la historia filogenética es preservada cuando los genomas son comparados"(Dykhuizen 2003, p.63).

15 Templeton (1992, p.164); Agustí (2003, p.87); Claridge (2010, p.96); y Chambers (2012, p.763).

${ }^{16}$ Pese a su innegable y aquí ya apuntada gravitación, no debe pensarse que el concepto biológico de especie sea el concepto de especie de la Nueva Síntesis. Conforme vemos, protagonistas tan importantes de esa reorganización de la Biología Evolucionaria como lo fueron George Gaylord Simpson y Julian Huxley nunca lo aceptaron plenamente. Simpson porque prefería ese concepto evolutivo de especie (Laporte 1994, p.156-7) al que aludiré más adelante; y Huxley (1963[1943], p.149) porque defendía un cierto pluralismo vinculado con los distintos modos de especiación. El concepto biológico de especie pudo ser el más difundido y considerado en la medida en que la Genética de Poblaciones operó como disciplina piloto de la Biología Evolucionaria; pero, en campos como la Paleontología, en donde la tutela de la Genética de Poblaciones no podía ser demasiado firme, la hegemonía del concepto biológico de especie no llegó a imponerse (cf. Agustí 2003, p.85). Y es interesante saber que un neodarwinista tan reputado como Maynard Smith (1993, p.229) llegó incluso a decir que la "la clasificación en especies se mantiene más por conveniencia que por el hecho que ella refleje la realidad".

Principia 17(3): 395-418 (2013). 
${ }^{17}$ Véase: Van Valen (1992 [1976], p.73); Génermont (1998, p.38); e incluso: Coyne \& Orr (2004, p.41).

${ }^{18} \mathrm{Al}$ respecto: Chapman \& Burke (2007, p.1773); Allano \& Clamens (2010, p.49); y Samadi \& Barberousse (2011, p.1576).

${ }^{19}$ Véase: Stebbins (1966, p.111); Ghiselin (1998, p.98); y Futuyma (2005, p.357).

${ }^{20}$ Peter Grant y Rosemary Grant (2008, p.29) afirman que "la especiación está completa cuando los miembros de dos poblaciones coexisten en simpatría sin cruzarse".

${ }^{21} \mathrm{Al}$ respecto, véase: Freire-Maia (1988, p.197); Coyne \& Orr (2004,p.39); Futuyma (2005, p.357); Allano \& Clamens (2010, p.50); y Diegues (2012, p.221).

${ }^{22}$ No es impertinente invocar esa división conceptual del trabajo en defensa del concepto biológico de especie. Mayr (1942, p.113) ya lo había al distinguir entre la definición de especie y los criterios para identificarlas.

${ }^{23}$ Al respecto, véase: Duchesneau (1997, p.27); Agustí (2003, p.84); De Keiroz (2003, p.199); Grene \& Depew (2004, p.294); Wilkins (2009, p.201); Ereshefsky (2010, p.415); y Richards (2010, p.102).

24 Ver: Richards (2007, p.219); De Keiroz (2011, p.27); y Mayden (2012, p.184).

${ }^{25}$ Duchesneau (1997, p.29); Ghiselin (1998, p.111); Grene \& Depew (2004, p.297); De Keiroz (2007, p.880); y Wilkins (2009, p.203).

${ }^{26}$ En Hennig (1968, p.62) no hay una definición evolutiva de especie: hay una definición biológica temporalizada (cf. Meier \& Willmann, 2000, p.31; Wiley \& Lieberman, 2011, p.35), jaqueada por las mismas dificultades que aquejan a la definición de Mayr.

${ }^{27}$ Hay formulaciones semejantes en: Wiley \& Mayden (2000, p.73); y Wiley \& Lieberman (2011, p.30).

${ }^{28}$ Al respecto, ver: Duchesneau (1997, p.32); y Wiley \& Lieberman (2011, p.37).

${ }^{29}$ Ver: Coyne \& Orr (2004, p.457); Wilkins (2009, p.216); y Dieguez (2012, p.224).

${ }^{30}$ Ver: Wiley (1992[1978], p.87); Duchesneau (1997, p.33); y Coyne \& Orr (2004, p.35).

${ }^{31}$ Sobre la diferencia entre argumentos ad rem y argumentos ad hominem, consúltese $E l$ arte de tener razón, póstumo de Arthur Schopenhauer (1996[1864], p.28-9). Impugnar una tesis señalando que su proponente ha bebido algunas copas de más, sería un argumento ad personam y no un argumento ad hominem: "éste se aparta del objetivo propiamente dicho para dirigirse a aquello que el adversario dijo o admitió. En cambio, cuando se arguye ad personam, no se apunta a la que el oponente dijo sino a su propia condición personal" (Schopenhauer 1996[1864], p.65).

32 Por eso mismo Hennig (1968, p.158) había llegado a considerar "dudoso" que se pudiese entender "a las especies en el seno de su medio ambiente como unidades de acción".

${ }^{33}$ Si los demás conceptos de especies pueden operar como criterios auxiliares que eventualmente pueden ayudarnos en la identificación de linajes de poblaciones microevolutivamente conectadas, creo que eso también se aplicará a las llamadas definiciones filogenéticas de especie (cf. Baum \& Donoghue [1995]2006, p.387; Ghiselin 1998, p.116; Coyne \& Orr 2004, p.459; Wilkins 2009, p.205; Claridge2010, p.96; González 2011, p.106; Wiley \& Lieberman 2011, p.37). Cuando se dice que una especie es el menor grupo monofilético diagnosticable (cf. Mishler \& Theriot, 2000, p.46-7), ya se está hablando de un criterio de identificación y no de una definición (Ver también: Eldredge \& Cracraft 1980, p.92; Cracraft 1987, p.341; Wheeler \& Platnick 2000, p.58; Mishler 2010, p.112).

Principia 17(3): 395-418 (2013). 
${ }^{34}$ Respecto de la reversibilidad de la especiación, véase: Mayr (1942, p.270); Coyne \& Orr (2004, p.37); y Grant \& Grant (2008, p.114).

35 Sobre la especiación por hibridación, véase: Huxley 1963[1943], p.324; Grant 1997 , p.18; y Mayr 1988, p.331.

${ }^{36}$ Sobre la especiación por hibridación, véase también: Arias et al. (1997, p.19); Mayhew (2006, p.134); y Chapman \& Burke (2007, p.1774)

${ }^{37}$ La mayor ocurrencia de transferencia lateral de genes que Daniel Dykhuizen (2003, p.63) apuntó como base de una definición biológica de especie aplicable a bacterias (ver nota 14), puede también considerarse como otro criterio que puede ayudar a delimitar linajes bacterianos de poblaciones microevolutivamente aisladas; es decir: especies bacterianas. Nótese, además, que el propio Dykhuizen (2003, p.63) apuntó a la selección natural como la posible responsable de la existencia de diferencias en la permeabilidad a la transferencia lateral de genes que existe entre diferentes linajes de bacterias.

Principia 17(3): 395-418 (2013). 